ISSN 0103-9954

\title{
A CADEIA PRODUTIVA DA AMÊNDOA DO BARU (Dipteryx alata Vog.) NO CERRADO: UMA ANÁLISE DA SUSTENTABILIDADE DA SUA EXPLORAÇÃO
}

\author{
THE ALMOND BARU'S PRODUCTION CHAIN (Dipteryx alata Vog.) IN CERRADO: AN \\ ANALYSIS OF THE SUSTAINABILITY OF ITS EXPLOITATION
}

\author{
Rogério Marcos Magalhães ${ }^{1}$
}

\begin{abstract}
RESUMO
Este artigo visa discutir os resultados obtidos com a pesquisa que buscou identificar, por meio de indicadores e de informações socioeconômicas, se a atividade de exploração da amêndoa do baru (Dipteryx alata Vogel) - uma espécie do Cerrado brasileiro - realizada por organizações privadas (empresas, cooperativas e associações representativas de agricultores familiares), estabelecidas em municípios goianos e no Distrito Federal, pode ser caracterizada como uma alternativa sustentável de geração de renda. Nesta pesquisa mensuraram-se cinco dimensões da sustentabilidade: ambiental, social, econômica, política e da saúde, por meio de indicadores, além de terem sido identificados os obstáculos enfrentados pelas organizações no âmbito da cadeia de produção do baru e proposto um modelo de produção para esta amêndoa do Cerrado. Os resultados demonstraram que, nas condições encontradas, a exploração do baru pelas organizações amostradas não se configura como uma atividade sustentável de geração de renda, uma vez que atende parcialmente ao pressuposto, segundo o qual a atividade para ser considerada sustentável deve possuir um equilíbrio entre as várias dimensões da sustentabilidade. Os obstáculos que as organizações da cadeia produtiva do baru enfrentam podem constituir em poderoso entrave à sua adequada gestão, contribuindo também para o comprometimento da sustentabilidade da atividade.
\end{abstract}

Palavras-chave: Baru; cadeia produtiva; sustentabilidade; extrativismo vegetal.

\begin{abstract}
This article seeks to discuss the results with the survey that sought to identify, by means of indicators and social-economical information, if the exploitation of baru nut (Dipteryx alata Vogel) - a Brazilian species from the savannah - carried out by the private sector (companies, cooperatives and representatives organizations of family farmer), established in municipalities in Goiás state and in the Federal District, which represents a sustainable alternative to generate income. This study measured the environmental, social, economic, political, and health dimensions of sustainability by using indicators. This study also searched identify the obstacles faced by organizations in the production chain of baru nut and proposed a production model for this nut of Cerrado. The results showed that under current circumstances, the extraction of baru nut by the sampled organizations is not a sustainable activity to generate income once it supports partially the premise that a sustainable activity must be a balance among the dimensions mentioned above. The obstacles that the baru nut chain has today can be a powerful one, not only to manage the chain itself but also to compromise the whole sustainability of this activity.
\end{abstract}

Keywords: Baru; production chain; sustainability; forest extraction.

1 Engenheiro Florestal, Dr., Analista Ambiental do Ministério do Meio Ambiente, SEPN 505 Norte, Bloco "B", 50 andar, CEP 70730-542, Brasília (DF), Brsil.rogerio.magalhaes@mma.gov.br 


\section{INTRODUÇÃO}

A extração de Produtos Florestais Não Madeireiros (PFNMs) pode ser considerada uma atividade fundamental para os moradores da região onde se explora tais recursos, uma vez que permite a manutenção da "floresta em pé", ou seja, a conservação das matrizes para uma exploração futura (SOUZA; SILVA, 2002).

A exploração de PFNMs sempre fez parte da história econômica brasileira, seja em maior ou menor intensidade. Primeiramente foi o pau-brasil (Caesalpinia echinata Lam.) explorado no Séc. XVI pelos europeus até a exaustão. No Século XVII, o Estado do Maranhão e Grão-Pará, já se constituíam em um imenso empório de produtos florestais, as chamadas "drogas do sertão" (SILVA, 1990). Tais produtos não eram somente explorados por grupos indígenas, também fizeram parte da vida do colono português.

Atualmente, unidades familiares de produção rural, em diversas regiões do país, praticam a extração de PFNMs como fonte de renda alternativa e de absorção de mão de obra familiar. $\mathrm{Na}$ maioria dos casos, esta atividade se realiza para complementar a renda do grupo, uma vez que a atividade principal seria a prestação de serviços, a lavoura e/ou pecuária. No entanto, em determinadas regiões, como na Amazônia, onde a exploração de produtos florestais é uma prática de destacada importância e que consome grande parte da força de trabalho familiar, a agricultura torna-se marginal, pelo fato de o cultivo de grãos e/ou pecuária ser praticado como uma atividade de subsistência que ocupa pouco tempo dos membros da família.

O baru (Dipteryx alata Vogel) é uma espécie vegetal pertencente à família Leguminosae (Fabaceae) com ocorrência ampla no Bioma Cerrado que vem sendo explorado economicamente. Os frutos são coletados entre julho e outubro por agricultores familiares que, após extrair sua amêndoa, vendem-na para empresas, cooperativas e associações representativas de agricultores familiares, que a processam, principalmente, para elaboração de produtos alimentícios que irão para o mercado.

No entanto, apesar da sua exploração ser uma atividade extrativista de baixo impacto ambiental, uma vez que somente os frutos maduros que caem ao solo são utilizados, ainda não foi avaliada a sustentabilidade da atividade ao longo da sua cadeia produtiva.

\section{As dimensões da sustentabilidade}

A sustentabilidade implica uma "necessária inter-relação entre justiça social, qualidade de vida, equilíbrio ambiental e a necessidade de desenvolvimento com capacidade de suporte" (JACOBI, 1999, p.180).

O presente estudo parte da premissa estabelecida por Sachs (2000) que qualquer atividade que tenha como propósito o planejamento do desenvolvimento, deve procurar o equilíbrio entre as várias dimensões da sustentabilidade. Estas dimensões devem ser integradas para que ocorra o processo do desenvolvimento sustentável. Desse modo, a atividade de extração da amêndoa do baru, para ser considerada sustentável, deve conciliar as dimensões ambiental, social, econômica, política e da saúde. O ponto de equilíbrio entre estas dimensões é medido pelo nível de bem-estar da comunidade humana envolvida na atividade.

A dimensão social da sustentabilidade é aquela que expressa a ideia de que somente uma sociedade menos desigual e com pluralismo político poderá produzir o desenvolvimento com bases sustentáveis (MMA, 2004).

A dimensão ambiental surge do princípio de que as populações - incluindo-se os atores institucionais e agentes econômicos - para garantir sua própria sobrevivência em longo prazo no planeta, deverão conhecer e manejar os recursos renováveis de modo a manter e/ou recuperar as condições químicas, físicas e biológicas do solo, bem como conservar e/ou recuperar a biodiversidade, as reservas naturais e os mananciais hídricos, assim como os demais recursos naturais (COSTABEBER; CAPORAL, 2002).

Adimensão econômica é alcançada mediante a gestão mais eficiente dos recursos e por um fluxo regular do investimento público e privado. Conforme essa orientação, a eficiência econômica deve ser avaliada por critérios macrossociais e não apenas pela lucratividade das empresas (PIRES, 1998). Esta sustentabilidade comporta a diversificação de atividades produtivas e um desenvolvimento econômico intersetorial equilibrado, segurança alimentar e contínua modernização dos instrumentos de produção (SACHS, 2000).

Segundo o mesmo autor, a sustentabilidade política refere-se ao reconhecimento do papel central das autoridades locais, comunidades e associações de cidadãos, na participação do planejamento local das ações direcionadas para a região onde vivem. 
A sustentabilidade da saúde tem um sentido específico no âmbito das estratégias de saúde pública. Para Matias e Nunes (2006), esta dimensão é alcançada por meio da incorporação da saúde em estratégias e políticas de desenvolvimento sustentável e o seu reconhecimento como um direito humano fundamental.

Assim, a sustentabilidade de um sistema agroextrativista pode ser compreendida como a capacidade desse sistema de manter-se ambientalmente equilibrado, socialmente justo e economicamente produtivo, levando bem-estar ao longo do tempo para aquela população humana que o explora.

\section{Cadeia de produção do baru}

As etapas produtivas da cadeia de produção da amêndoa do baru identificada durante os estudos guardam certa semelhança com o conceito de filière, que se traduz na sequência de operações tecnológicas, de produção, distintas e dissociáveis, exigidas para a elaboração de um bem acabado, ou um conjunto de bens, para o consumo final.

Acadeia produtiva da baru pode ser entendida como uma cadeia produtiva da biodiversidade. Sua diferença com relação às cadeias tradicionais é a sua necessidade de interagir com a bioindústria e de outro lado com as comunidades rurais que exploram o fruto (ENRIQUEZ, 2008).

Pimentel (2008) analisou as tecnologias empregadas em todas as etapas do processo produtivo dos PFNMs oriundos do baru em unidades produtivas do Cerrado, e concluiu que as tecnologias adotadas para a quebra do fruto são variadas e suficientes para as diversas realidades de campo encontradas.

No entanto, o que se verifica é que a utilização da foice adaptada para a extração da amêndoa do baru, apesar de ser uma tecnologia simples amplamente adotada, não é considerada suficiente pelos produtores rurais que exploram a espécie. Este instrumento proporciona a um homem quebrar, em um dia, uma quantidade de frutos suficiente para obter $2 \mathrm{~kg}$ de sementes, o que aponta para uma produtividade reconhecidamente baixa pelos produtores rurais.

Apesar do desenvolvimento de alguns protótipos de máquinas manuais e elétricas para a extração da amêndoa do baru, o mercado ainda não conta com modelos de eficiência comprovada. Algumas microempresas, cooperativas e associações representativas do agricultor familiar dispõem de máquina manual ou elétrica, porém, são artesanais e fabricadas sob encomenda.

\section{Obstáculos}

Empresas/cooperativas/associações que operam com produtos derivados de espécies vegetais nativas do Cerrado enfrentam dificuldades para viabilizar essa forma de produção. Além de um marco regulatório bastante confuso e incompleto, sofrem com a falta de informações sobre $o$ comportamento do mercado, com a falta de domínio das etapas de processamento e beneficiamento do produto e ainda se deparam com a inadequação ou até mesmo a inexistência de infraestrutura básica, como energia elétrica, água encanada e rede viária para o escoamento da produção.

Vários autores (SAWYER, 2009; ENRIQUEZ, 2008; GONÇALO, 2006; CIRAD, 2001; MAY, 2001; SAWYER, REE, PIRES, 1997), abordam o problema dos obstáculos que incidem sobre as cadeias produtivas de PFNMs na tentativa de identificá-los e propor soluções que venham a minimizar os seus efeitos sobre as populações rurais que exploram esses produtos.

Além desses fatores limitantes à produção diretamente relacionados ao uso de componentes da biodiversidade, existem aqueles vinculados à própria natureza das empresas, cooperativas e associações. Tomando como exemplo as microempresas, podese dizer que enfrentam várias dificuldades para se manterem ativas no mercado. O SEBRAE (2007) enumerou vários motivos que levam essas pessoas jurídicas a encerrarem as suas atividades. Entre as empresas extintas, as causas que mais se destacaram em 2005 para que fechassem as portas foram: carga tributária elevada (para 43\% dos empresários), concorrência muito forte e falta de clientes (para $25 \%$ e $27 \%$, respectivamente), falta de capital de giro (para $37 \%$ dos empresários que responderam a pesquisa) e falta de mão de obra qualificada (para $16 \%$ deles). Outros fatores também contribuíram para a mortalidade dessas empresas, como a falta de crédito bancário, a inadimplência, a falta de conhecimentos gerenciais e o desconhecimento do mercado.

Desta forma, ao se considerarem os obstáculos que as pessoas jurídicas enfrentam para explorar produtos da vegetação nativa do Cerrado, não se pode deixar de levar em conta esses condicionantes. 
O trabalho procurou demonstrar que apesar de a exploração da amêndoa do baru ser uma atividade econômica que vem beneficiando um considerável número de organizações privadas (empresas, cooperativas e associações representativas do agricultor familiar), estabelecidas em municípios goianos e no Distrito Federal, não pode ser caracterizada como uma alternativa sustentável de geração de renda, uma vez que atende parcialmente ao pressuposto segundo o qual a atividade para ser considerada sustentável deve possuir um equilíbrio entre as várias dimensões da sustentabilidade.

Nesse sentido, para o alcance do objetivo acima descrito, procurou-se medir a sustentabilidade da atividade por meio de indicadores, gerandose também informações a respeito dos obstáculos enfrentados pelas organizações privadas no âmbito daquela cadeia produtiva e, ao final, propondo-se um modelo de produção para a amêndoa do baru.

\section{MATERIAL E MÉTODOS}

\section{Mensuração da sustentabilidade}

As organizações amostradas pertencem ao ramo da produção de alimentos.

Inicialmentefoimensuradaasustentabilidade da cadeia produtiva do baru a partir de um índice resultante da agregação de indicadores distribuídos por cinco dimensões da sustentabilidade: ambiental, econômica, social, política e da saúde. Para cada uma dessas dimensões foram criados indicadores com o propósito de mensurar a sustentabilidade da atividade de exploração desta amêndoa por organizações privadas.

Os indicadores foram criados após revisão da bibliografia sobre sustentabilidade em empresas e cooperativas de médio e grande porte, uma vez que muito pouco foi encontrado na literatura sobre sustentabilidade em microempresas. A partir dessa constatação, procurou-se adaptar aqueles indicadores às condições dessas empresas.

Partiu-se do pressuposto que um sistema de indicadores deve representar o mais fielmente possível o desenvolvimento sustentável, embora se acredite não existir ainda o indicador perfeito, pois todos eles possuem alguma deficiência quando se trata de mensurações envolvendo as dimensões da sustentabilidade.

Para chegar-se ao grau da sustentabilidade da atividade de exploração do baru foi adotado o seguinte procedimento:
Foram elaborados questionários com indicadores dirigidos às organizações que processam a amêndoa do baru;

Em seguida foram aplicados os questionários nesse segmento da cadeia produtiva;

Os resultados obtidos com a aplicação dos questionários serviram de base para o cálculo do Índice Individual de Sustentabilidade (Iw) para cada instituição;

na sequência, foi calculado o Índice de Sustentabilidade $(I S)$ para estas organizações;

foi estabelecido o grau de sustentabilidade (Tabela 1) das organizações privadas, por categoria, para fins de comparação.

\section{Índice Individual de Sustentabilidade (Iw)}

Este índice foi calculado para as cinco dimensões empregando-se a seguinte fórmula (RABELO; LIMA, 2007; BARRETO; KHAN; LIMA, 2005; KHAN; PASSOS, 2001; FERNANDES; SILVA; KHAN, 1997):

$$
I w=\frac{1}{n} \sum\left(\frac{\sum_{i=1}^{m} E i j}{\sum_{i=1}^{m} E \max i}\right)
$$

Em que: $I w=$ Índices que comporão o índice de sustentabilidade econômico, social, ambiental, político e da saúde; Eij = Escore do i-ésimo indicador de $I w$ obtido do j-ésimo questionário; $E$ max $i=$ Escore máximo do $i$-ésimo indicador de $I w$ obtido do $j$-ésimo questionário; $i=1, \ldots, \mathrm{m}$, número de indicadores; $j=1, \ldots, \mathrm{m}$, número de questionários aplicados; $w=1, \ldots, 5$, número de índices que comporão o índice de sustentabilidade.

De acordo com a equação acima, quanto mais próximo de 1 o valor do índice $I w$, melhor o desempenho do objeto de estudo, ou seja, maior a sustentabilidade das atividades desenvolvidas pelas organizações privadas que fazem parte da cadeia produtiva do baru. O indicador está dentro do intervalo: $0<I w \leq 1$.

Para esta metodologia, o valor do índice nunca atingirá zero, pois o fato da instituição privada explorar o baru, já indica o acúmulo de pontos.

Os questionários contaram com perguntas cujas respostas predeterminadas receberam pontuação de 0 a 4 . Para se calcular o Índice Individual de Sustentabilidade (Iw), somou-se a pontuação obtida por cada respondente, por 
questionário, dividido pelo número máximo de pontos que poderia ser obtido.

\section{Índice de Sustentabilidade (IS)}

Os indicadores ambiental, econômico, social, político e da saúde foram utilizados para calcular o Índice de Sustentabilidade (IS). Atribuiuse peso igual a cada dimensão analisada. $\mathrm{O}$ valor de $I S$ é a média aritmética dos cinco índices mencionados. Quanto mais próximo de 1 maior o grau de sustentabilidade. $\mathrm{O}$ indicador está dentro do intervalo: $0<I S \leq 1$.

Para o cálculo do $I S$, a expressão utilizada foi a seguinte (RABELO; LIMA, 2007; BARRETO; KHAN; LIMA, 2005; KHAN; PASSOS, 2001; FERNANDES; SILVA; KHAN, 1997):

$$
I S=\frac{1}{k} \sum_{w=1}^{k} I w
$$

Em que: $I S=$ Índice de sustentabilidade; $w=$ valor do $w$-ésimo indicador; $\mathrm{w}=1, \ldots \mathrm{k}$.

\section{Grau de sustentabilidade}

O grau de sustentabilidade é obtido utilizando-se o valor dos Índices de Sustentabilidade (IS), tornando possível conhecer o grau de sustentabilidade da atividade de exploração do baru pelas organizações estudadas. Compreende uma escala que vai de 0 até 1 , divididos em três graus distintos: baixo, médio ealto nível de sustentabilidade (Tabela 1). Abaixo de 0,500 e acima de 0 , a atividade se caracteriza por não sustentabilidade devendo o poder público, em conjunto com a sociedade, tomar as medidas necessárias para sanear os problemas que fizeram o índice chegar até esse nível e tentar tornar a atividade o mais sustentável possível. Quando o valor do índice fica entre 0,500 e 0,799 significa que a atividade estudada é razoavelmente sustentável, mas sujeita às várias medidas para que chegue o mais próximo possível de 1 . Assim, à medida que crescem na direção de 1 , vão aumentando as condições de sustentabilidade.

Para a classificação da sustentabilidade das organizações privadas estabeleceu-se o critério abaixo, adaptado do Índice de Desenvolvimento Humano (IDH) do United Nations Development Program - UNDP (1998):

\section{Identificação dos obstáculos enfrentados pelas organizações privadas no âmbito da cadeia produtiva do baru}

Para a identificação dos obstáculos enfrentados pelas organizações no âmbito da cadeia produtiva do baru, foi exposto ao representante da instituição um documento onde se encontravam enumerados vários obstáculos ao bomfuncionamento e crescimento da instituição. Esta lista foi elaborada com base na literatura sobre o assunto. Em seguida, o entrevistado foi estimulado a marcar aquelas que corresponderiam às dificuldades que a sua empresa/ associação/cooperativa vinha enfrentando.

\section{Origem dos dados}

Os dados primários foram obtidos a partir da aplicação de questionários junto aos representantes de organizações privadas que participam da cadeia produtiva do baru.

Foram selecionadas 21 organizações pelo método não probabilístico, uma vez que dependeu do julgamento do pesquisador. Neste caso, foram escolhidas aquelas organizações que utilizam o baru como matéria-prima para os produtos que são enviados para o mercado de varejo, ou para outras empresas processadoras. O outro critério foi o de que estas empresas/associações/cooperativas deveriam estar estabelecidas próximas aos municípios de Formosa e Pirenópolis, em Goiás, regiões produtoras da amêndoa do baru.

Foi amostrado todo o universo das organizações privadas que utilizam o baru como matéria-prima e que estão estabelecidas naqueles

TABELA1: Grau de sustentabilidade das organizações privadas estudadas, segundo os índices obtidos.

TABLE 1: Degree of sustainability of the private organizations studied according to the indices obtained.

\begin{tabular}{cc}
\hline Grau & Intervalo do índice \\
\hline Baixo nível de sustentabilidade & $0<I S \leq 0,499$ \\
Médio nível de sustentabilidade & $0,500 \leq I S \leq 0,799$ \\
Alto nível de sustentabilidade & $0,800 \leq I S \leq 1,000$ \\
\hline
\end{tabular}


municípios goianos e/ou no Distrito Federal.

\section{Proposição do modelo produtivo do baru}

Para a proposição do modelo de produção do baru no Cerrado goiano foram levantados dados a partir dos questionários aplicados, da observação direta, de entrevistas semiestruturadas realizadas e da análise de documentos. Os dados primários foram obtidos diretamente dos agricultores familiares e das organizações privadas que processam a amêndoa, atores principais da cadeia produtiva do baru. Esses dados permitiram a confrontação do modelo de produção do baru encontrado com os modelos de exploração de recursos naturais vegetais propostos por Homma (1993), Rego (1992) e Drummond (1996).

\section{RESULTADOS E DISCUSSÃO}

\section{Índice de sustentabilidade}

Com exceção de duas associações civis, uma cooperativa, um empreendedor individual e uma empresa de médio porte, com 250 empregados, o restante das organizações são microempresas. Todos os responsáveis pelas microempresas afirmaram enfrentar dificuldades para viabilizar o seu negócio, como o fornecimento irregular da amêndoa em razão da sazonalidade do fruto do

TABELA 2: Índices de Sustentabilidade Individual (Iw) por instituição amostrada, em 2010.

TABLE 2: Individual Sustainability Index (Iw) by institution sampled in 2010.

\begin{tabular}{|c|c|c|c|c|c|c|c|}
\hline $\mathrm{N}^{\mathrm{o}}$ ordem & Organizações & $\begin{array}{c}\text { Índice } \\
\text { Ambiental }\end{array}$ & $\begin{array}{l}\text { Índice } \\
\text { Social }\end{array}$ & $\begin{array}{c}\text { Índice } \\
\text { Econômico }\end{array}$ & $\begin{array}{l}\text { Índice } \\
\text { Político }\end{array}$ & $\begin{array}{l}\text { Índice da } \\
\text { Saúde }\end{array}$ & $\begin{array}{l}\text { Índice } \\
\text { Geral }\end{array}$ \\
\hline 1 & Indústria alimentícia & 0,583 & 0,556 & 0,667 & 0,250 & 0,000 & 0,411 \\
\hline 2 & Indústria alimentícia & 0,583 & 0,778 & 0,667 & 0,250 & 0,250 & 0,506 \\
\hline 3 & Indústria alimentícia & 0,500 & 0,667 & 0,600 & 0,500 & 0,500 & 0,553 \\
\hline 4 & Indústria alimentícia & 0,500 & 0,667 & 0,800 & 0,250 & 0,500 & 0,543 \\
\hline 5 & Pousada & 0,500 & 0,667 & 0,467 & 0,500 & 0,750 & 0,577 \\
\hline 6 & Indústria alimentícia & 0,417 & 0,222 & 0,533 & 0,000 & 0,000 & 0,234 \\
\hline 7 & Indústria alimentícia & 0,667 & 0,556 & 0,467 & 0,500 & 0,250 & 0,488 \\
\hline 8 & Associação/Cooperativa & 1,000 & 0,778 & 0,400 & 0,750 & 0,000 & 0,586 \\
\hline 9 & Restaurante & 0,500 & 0,222 & 0,400 & 1,000 & 0,000 & 0,424 \\
\hline 10 & Restaurante & 0,417 & 0,778 & 0,600 & 0,500 & 0,250 & 0,509 \\
\hline 11 & Restaurante & 0,167 & 0,667 & 0,667 & 0,500 & 0,500 & 0,500 \\
\hline 12 & Indústria alimentícia & 0,917 & 0,556 & 0,533 & 0,250 & 0,500 & 0,551 \\
\hline 13 & Empreendimento individual & 0,417 & 0,111 & 0,333 & 0,000 & 0,000 & 0,172 \\
\hline 14 & Associação/Cooperativa & 0,667 & 0,556 & 0,733 & 0,250 & 0,250 & 0,491 \\
\hline 15 & Restaurante & 0,250 & 0,333 & 0,667 & 0,000 & 0,250 & 0,300 \\
\hline 16 & Restaurante & 0,417 & 0,667 & 0,733 & 0,250 & 0,500 & 0,513 \\
\hline 17 & Restaurante & 0,250 & 0,222 & 0,533 & 0,250 & 0,250 & 0,301 \\
\hline 18 & Restaurante & 0,333 & 0,556 & 0,600 & 0,500 & 0,250 & 0,448 \\
\hline 19 & Restaurante & 0,667 & 0,667 & 0,667 & 0,500 & 0,000 & 0,500 \\
\hline 20 & Associação/Cooperativa & 0,333 & 0,667 & 0,533 & 0,250 & 0,000 & 0,357 \\
\hline 21 & Associação/Cooperativa & 0,333 & 0,444 & 0,267 & 0,000 & 0,000 & 0,209 \\
\hline- & Índices de sustentabilidade & 0,496 & 0,540 & 0,565 & 0,345 & 0,238 & 0,437 \\
\hline
\end{tabular}


baru, inexistência de equipamentos e de tecnologia adequadas às necessidades do ramo no qual atuam, falta de divulgação do baru ao consumidor, falta de capacitação para o atendimento às exigências de qualidade de produção, falta de informações técnicas sobre a fabricação de produtos a base de baru, falta de capital de giro, falta de linhas de crédito bancário para empresas que operam com produtos da biodiversidade, preço elevado do produto a base de baru, elevado custo administrativo da empresa, baixa qualidade da amêndoa de baru entregue pelo fornecedor, legislação sanitária inadequada às atividades que a empresa desenvolve, carga tributária elevada, falta de experiência no gerenciamento do empreendimento, excesso de burocracia do poder público para a regularização das operações da empresa/cooperativa/associação, alto risco do crédito em razão da maior vulnerabilidade do tipo de empresa que administra, insuficiência de garantias reais para oferecer às instituições de crédito bancário e problemas com a logística operacional.

O canal de distribuição predominante é a venda direta ao consumidor. Das 21 organizações amostradas, 18 adotam esse canal.

A organização processadora do baru que obteve o Índice de Sustentabilidade Individual (Iw) mais alto $(0,586)$ foi uma associação com tradição em iniciativas na conservação e utilização de componentes da biodiversidade (Tabela 2). Essa organização investe no uso sustentável da fauna e flora do Cerrado, com trabalhos relevantes na domesticação de fauna e também com a produção de fitoterápicos, cuja matéria-prima é fornecida por agricultores familiares. Distribui os medicamentos preferencialmente por meio de farmácias populares, sendo esta distribuição dirigida para a população de baixa renda.

$\mathrm{O}$ Iw mais baixo $(0,172)$ entre as organizações estudadas foi alcançado por um empreendedor individual que admitiu ser a busca pelo lucro a única preocupação do seu negócio, não estando entre as suas prioridades o atendimento às demais dimensões da sustentabilidade.

O Índice de Sustentabilidade (IS) geral dos empreendimentos analisados foi de 0,437 , apontando para um baixo grau de sustentabilidade (Figura 1), nos termos da escala da UNDP adaptada (Tabela 1). Os dados coletados junto a essas organizações evidenciaram a preocupação predominante com a sustentabilidade econômica e a reduzida importância para com as outras dimensões. Empreendedores consultados justificaram a não adequação às medidas que poderiam melhorar a sustentabilidade da sua instituição, em razão do alto custo exigido para a sua implantação, principalmente medidas relativas às sustentabilidades social, ambiental e da saúde. Outros justificaram a não adoção dessas medidas pelo fato de desconhecerem-nas.

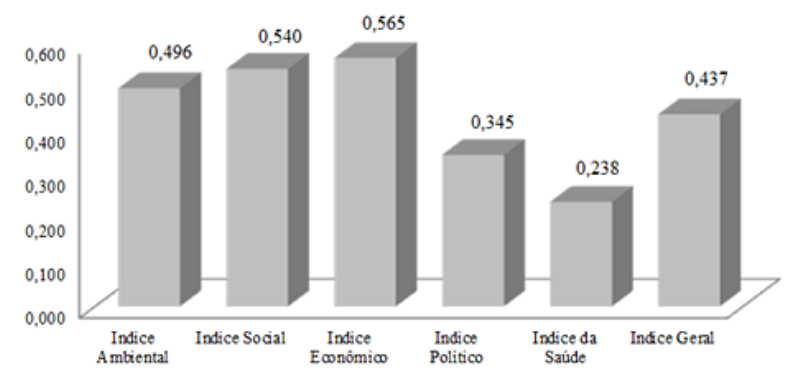

FIGURA 1: Índice de Sustentabilidade (IS) das organizações estudadas, por dimensão da sustentabilidade, em 2010.

FIGURE1: Sustainability Index $(S I)$ of the institutions studied by sustainability dimension in 2010.

A dimensão econômica foi a que obteve o maior Iw $(0,565)$, seguida da social $(0,540)$ e ambiental $(0,496)$. As dimensões política e da saúde foram as que obtiveram os índices mais baixos (Figura1). O valor alcançado pela dimensão política $(I w=0,345)$ denota a pouca participação ou mesmo a falta de oportunidade das organizações na formulação de políticas voltadas para o setor que atuam. Medidas para alcançar uma boa sustentabilidade da saúde como assistência médicohospitalar gratuita para os empregados, prevenção de acidentes de trabalho e lesões por esforço repetitivo, praticamente não estão entre as prioridades das organizações.

\section{Obstáculos apontados pelas organizações que utilizam o baru}

Os obstáculos que mais receberam indicações foram: "Fornecimento irregular da amêndoa do baru em razão da sazonalidade do fruto do baru", com dezoito, seguido de "Inexistência de equipamentos e de tecnologia adequadas às necessidades do ramo no qual atua", com quinze e "Falta de divulgação do baru ao consumidor", com treze indicações.

Do total das organizações estudadas, $85,71 \%$ têm problema com o fornecimento da amêndoa do 
baru. Essa irregularidade pode ter como causas a sazonalidade da frutificação da espécie e/ou a falta de capacidade do agricultor para extrair a amêndoa do baru em uma quantidade suficiente para tornar o fornecimento constante. De qualquer forma, essa irregularidade faz com que as organizações diminuam seu interesse pela amêndoa, ou mesmo deixem de utilizá-la na composição dos produtos que comercializam.

A frase "inexistência de equipamento e tecnologia adequados às necessidades do ramo do empreendimento" indica uma carência de máquinas no mercado e de tecnologias disponíveis para o processamento do produto. Os proprietários afirmaram que as máquinas que possuem para processar o baru são adaptadas, o que diminui muito a produtividade. Afirmaram que a tecnologia para o processamento do produto praticamente inexiste, o que leva o empreendedor a dispensar tempo e recursos valiosos na busca de técnicas mais apuradas.

Quanto à afirmativa "Falta de divulgação do baru ao consumidor", entendem que a amêndoa é pouco conhecida pela população e que são reduzidas as iniciativas para divulgar o produto. Alegam que, nos centros consumidores, poucas são as pessoas que conhecem a amêndoa, o que mereceria iniciativas do poder público e da iniciativa privada no sentido de melhor divulgar esse produto.

A legislação sanitária não parece ser um gargalo para as organizações privadas que utilizam a amêndoa do baru. O obstáculo reproduzido na frase "Legislação sanitária inadequada às atividades que a empresa desenvolve" recebeu somente oito indicações. A maioria dos entrevistados alegou que, apesar da legislação ser extensa, encontra relativa facilidade em manter contato com os órgãos públicos quando surgem problemas.

\section{Modelo produtivo do baru}

O trabalho de campo forneceu elementos para a estruturação e a identificação da cadeia produtiva do baru, além de elementos necessários para a análise do papel dos atores que dela participam.

O modelo genérico da cadeia produtiva do baru encontrada em alguns municípios do estado de Goiás e no Distrito Federal pode ser representado nos termos da Figura 2.

A partir da identificação da cadeia produtiva do baru foi possível propor um modelo produtivo para esta amêndoa. A Figura 3 ilustra o modelo produtivo do baru encontrado nas áreas estudadas tendo o agricultor familiar, as organizações privadas e o consumidor como atores principais.

Nesse modelo, a relação comercial entre os compradores da amêndoa (associações/ cooperativas, empresas, atravessador, consumidor, Governo Federal) e o agricultor familiar que coleta o baru é fragmentada em razão da irregularidade no fornecimento do produto, que pode ocorrer em decorrência de fatores tais como: a sazonalidade da frutificação, irregularidade nas quantidades produzidas pelas árvores (nos anos de 2009 e 2010, a produção de frutos foi pequena nos dois municípios estudados quando comparada ao ano de 2008. Segundo atravessadores entrevistados, em função da safra do baru ter sido pequena nos dois últimos anos na região, foram obrigados a adquirir o fruto nos estados de Minas Gerais e Tocantins.), a falta de local apropriado para estocar o produto, a descapitalização e a dificuldade de acesso ao crédito, cuja falta complica no armazenamento do fruto em quantidade suficiente para a entressafra.

Outros fatores que podem contribuir para a fragmentação dessa cadeia são: o pouco conhecimento demonstrado pelo agricultor/coletor sobre o processamento do fruto, a sua dificuldade histórica de se organizar socialmente e a sua pouca ou nenhuma experiência em lidar com o mercado.

Essas características têm reflexo diretamente na organização das associações/cooperativas, uma vez que, ao assumirem a sua direção, os associados tornam evidentes essas deficiências. Somam-se a isso outros fatores que contribuem para o insucesso de empreendimentos dessa natureza, como a baixa participação dos produtores no empreendimento, a falta crônica de capital de giro para o custeio e comercialização e a sua vulnerabilidade frente ao mercado, principalmente em razão de seus dirigentes encontrarem dificuldade com a gestão de negócios e a dificuldade para atender aos procedimentos administrativos exigidos pela legislação.

Essas organizações costumam vender a sua produção em eventos, feiras, a empresas e para o mercado institucional. Quando enfrentam o mercado é que surgem as grandes dificuldades e desafios para os seus representantes. Outros obstáculos são: a falta de mobilização, a tempo e a hora para a obtenção de informações a respeito dos preços e do seu comportamento; falta de conhecimento sobre quem irá comprar a produção; dificuldade para a obtenção de informações a respeito dos preços, 


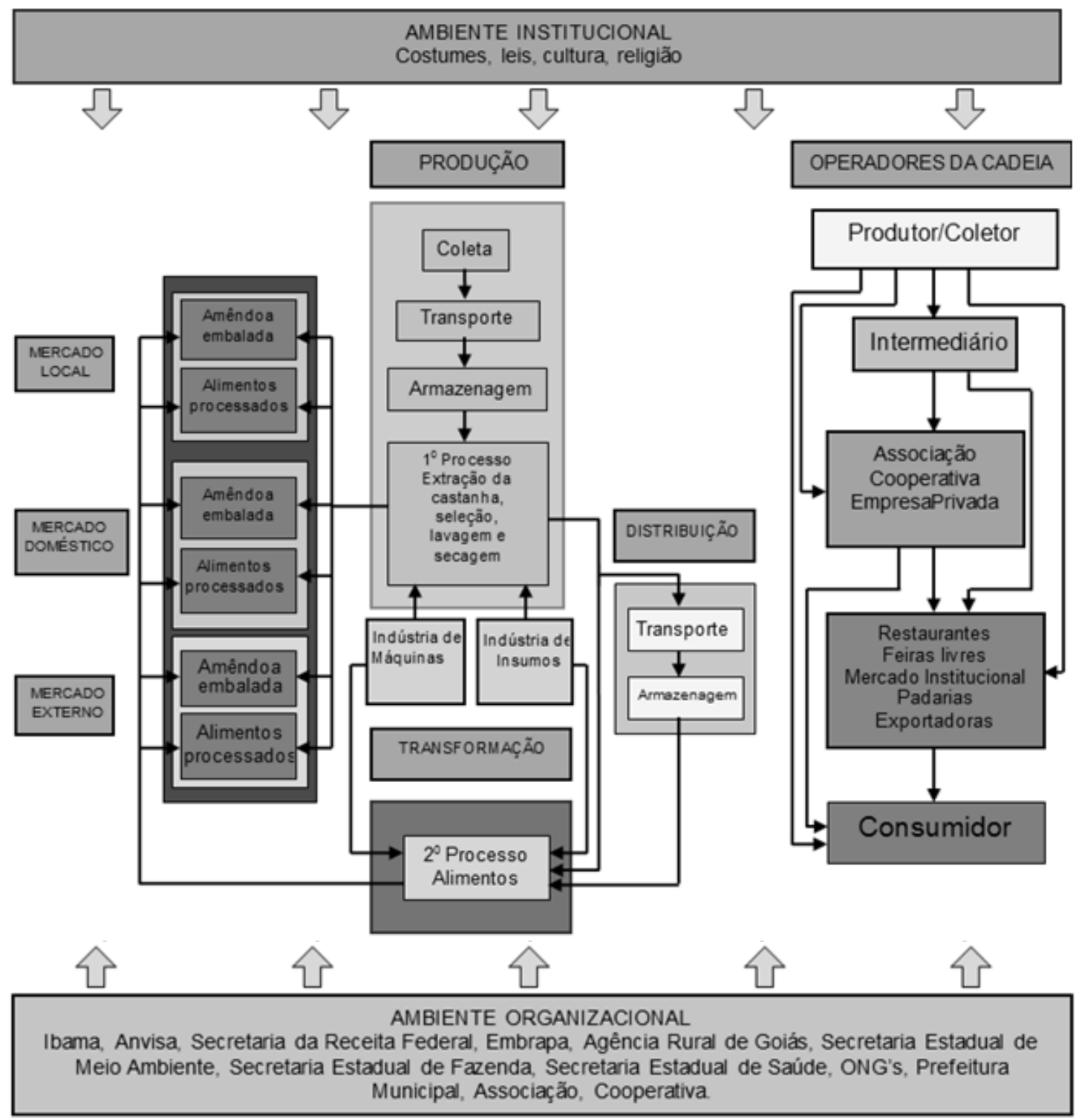

FIGURA 2: Modelo genérico da cadeia produtiva do baru no Estado de Goiás e Distrito Federal. FIGURE 2: Generic model of the productive chain of baru nut in Goiás state and in Distrito Federal.

valor do frete e compradores antes de movimentar a carga; dificuldade para organizar a logística de transporte das mercadorias.

\section{CONCLUSÕES}

O trabalho demonstrou que a atividade de exploração da amêndoa do baru pelas organizações amostradas não se configura como uma atividade sustentável de geração de renda, uma vez que não foi identificado um equilíbrio entre as dimensões da sustentabilidade analisadas.

Nas empresas/cooperativas/associações, o Índice de sustentabilidade de maior valor foi o econômico $(I S=0,565)$, demonstrando uma maior preocupação na viabilização econômica do empreendimento e ignorando as outras dimensões da sustentabilidade. Assim, os resultados obtidos sugerem que a primeira preocupação dos representantes dessas organizações consiste em manter o seu empreendimento economicamente viável, relegando a um segundo plano a adoção de medidas que levem sua empresa/cooperativa/ associação a alcançar um equilíbrio entre as dimensões analisadas.

A sustentabilidade política com valores 




FIGURA 3: Modelo conceitual de exploração do fruto do baru encontrado em municípios do estado de Goiás e no Distrito Federal, 2010.

FIGURE 3: Conceptual model of exploitation of baru nut found in municipalities in Goiás state and in the Federal District, 2010.

baixos pode ser considerada como um indicador da deficiência do Estado no estímulo a processos participativos capazes de assegurar o exercício da cidadania, em ações que busquem a superação das deficiências dos serviços públicos prestados e no fornecimento da infraestrutura básica para que as organizações possam alcançar um bom desempenho.

Os obstáculos que as organizações da cadeia produtiva do baru enfrentam podem se constituir em poderoso entrave à sua adequada gestão, contribuindo também para o comprometimento da sustentabilidade da atividade de exploração da amêndoa do baru.

O estudo da cadeia produtiva do baru permitiu identificar um modelo de produção com características diferentes daqueles propostos para explicar o extrativismo, particularmente no que diz respeito à organização da produção nas unidades agrícolas familiares. A atividade de coleta do fruto do baru no Cerrado goiano, moldado por fatores econômicos, sociais, ecológicos e culturais locais, difere dos modelos propostos por Homma (1993), Rego (1992) e Drummond (1996) para explicar o extrativismo amazônico.

Convém salientar que, no âmbito das incertezas que envolvem as mensurações da sustentabilidade de atividades produtivas, não se sabe se o número de indicadores adotados no presente estudo irá refletir o grau de sustentabilidade da atividade de exploração do baru, ou mesmo se seu conjunto é o mais indicado para uma tomada de decisão. No entanto, selecionaram-se aqueles indicadores que se julgou poder melhor expressar a realidade encontrada em campo.

\section{AGRADECIMENTOS}

Ao Instituto Sociedade, População e Natureza - ISPN, que proporcionou recursos financeiros do Projeto "FLORELOS: Elos ecossociais entre as florestas brasileiras - modos de vida sustentáveis em paisagens produtivas", desenvolvido com o apoio financeiro da União Europeia, para a realização desse estudo. 


\section{REFERÊNCIAS BIBLIOGRÁFICAS}

BARRETO, R. C. S.; KHAN, A. S.; LIMA, P. V. P. S. Sustentabilidade dos assentamentos no município de Caucaia-CE. Revista de Economia e Sociologia Rural [online], Brasília, v. 43, n. 2, p. 225-247, abr./ jun. 2005.

CENTRE DE COOPÉRATION

INTERNATIONALE DE LA RECHERCHE AGRONOMIQUE POUR LE DÉVELOPPEMENT - CIRAD. Projeto para o fortalecimento das atividades extrativistas no estado do Acre. Relatório Final. 2001. Disponível em: $<\mathrm{http}: / /$ www.florestavivaextrativismo.org.br/download/ documentos/2001_Acre_extrativismo_cirad.pdf $>$. Acesso em: 15 jun. 2010.

COSTABEBER, J. A.; CAPORAL, F. R. Análise multidimensional da sustentabilidade: uma proposta metodológica a partir da agroecologia. Agroecologia e Desenvolvimento Rural Sustentável. Porto Alegre, v. 3, n. 3, p.+-* 70-85, jul/set 2002. Disponível em: http:/www.intra.seagro.go.gov. br/admin/arq_doc/arquivos/seagro_35_382.pdf $>$. Acesso em: 12 fev. 2009.

DRUMMOND, J. A. A extração sustentável de produtos florestais na Amazônia Brasileira. Estudos - Sociedade e Agricultura. Rio de Janeiro, v. 6, p. 116-137, 1996.

ENRÍQUEZ, G. E. V. Desafios da sustentabilidade da Amazônia: biodiversidade, cadeias produtivas e comunidades extrativistas integradas. 2008. $460 \mathrm{f}$. Tese (Doutorado em Desenvolvimento Sustentável) - Centro de Desenvolvimento Sustentável, Universidade de Brasília, Brasília, 2008.

FERNANDES, A. V; SILVA, L. M. R.; KHAN, A. S. Reserva extrativista do Rio Cajari: sustentabilidade e qualidade de vida. Revista de Economia e Sociologia Rural. Brasília, v. 35, n. 3, p. 119-140, jul./set. 1997.

GONÇALO, J. E. Gestão e comercialização de produtos florestais não madeireiros (pfnm) da biodiversidade no Brasil. In: ENEGEP, 26., 2006, Fortaleza. Anais... Fortaleza, 2006. Disponível em: $\quad<$ http://www.abepro.org.br/biblioteca/ ENEGEP2006_TR520346_8257.pdf>. Acesso em: 21 mar. 2010.

HOMMA, A. K. O. Extrativismo vegetal na Amazônia: limites e oportunidades.Brasília: Embrapa-SPI, 1993.

JACOBI, P. R. Meio ambiente e sustentabilidade. Revista de Desenvolvimento e Meio Ambiente. São Paulo, 1999, p. 175-183. Disponível em:<http:// www.cepam.sp.gov.br>. Acesso em: 05 jan. 2009. KHAN, A. S.; PASSOS, A. T. B. Reforma agrária solidária e qualidade de vida dos beneficiários no estado do Ceará. Revista de Economia e Sociologia Rural. Brasília, v. 39, n. 4, p. 93-117, out./dez. 2001. MATIAS, M.; NUNES, J. A. Sustainable healthy?Healthy, environment and the politics of sustainability. Oficina do CES, Coimbra, n. 209, abril/2004. Disponível em: $<$ https://estudogeral.sib. uc.pt/jspui/bitstream/10316/11062/1/Health, \%20 environment $\% 20$ and $\% 20$ the $\% 20$ politics $\% 20$ of $\% 20$ sustainability.pdf $>$. Acesso em: 25 mai. 2010. No texto está 2004. Verificar.

MAY, P. H. (Org.) Compilacion y analisis sobre losproductosforestales no madereros (PFNM) enel Brasil: relatório técnico. Santiago: FAO, 2001. $88 \mathrm{p}$.

MINISTÉRIO DO MEIO AMBIENTE - MMA. Agenda 21 brasileira: ações prioritárias/Comissão de Políticas de Desenvolvimento Sustentável e da Agenda 21 Nacional. 2 ed., Brasília: MMA, 2004. $158 \mathrm{p}$.

PIMENTEL, N. M. Processo produtivo para o aproveitamento dos produtos florestais não madeireiros do baru (Dipteryxalata Vog.). 2008. 107 f. Dissertação (Mestrado em Ciências Florestais) - Departamento de Engenharia Florestal, Universidade de Brasília, Brasília, 2008.

PIRES, M. O. A trajetória do conceito de desenvolvimento sustentável na transição paradigmática. In: BRAGA, M. L. S.; DUARTE, L. M. G. (Orgs.) Tristes Cerrados: sociedade e biodiversidade. Brasília: Paralelo 15, 1998. p. 63-92.

RABELO, L. S.; LIMA, P. V. P. S. Indicadores de sustentabilidade: a possibilidade de mensuração do desenvolvimento sustentável. Revista Eletrônica do Prodema. Fortaleza, v. 1, n. 1, p. 55-76, dez. 2007.

RÊGO, J. F. do. Amazônia: do extrativismo ao neoextrativismo. Ciência Hoje, Rio de Janeiro, v. 25, n. 147 , p. $62-65,1992$.

SACHS, I. Caminhos para o desenvolvimento sustentável. Rio de Janeiro: Garamond, 2000. 96 p. SAWYER, D. R. Entraves regulatórios de atividades extrativistas na Amazônia: problemas, enfrentamento e soluções. Nota Técnica elaborada para o Centro de Gestão de Estudos Estratégicos (CGEE), com apoio da Secretaria de Assuntos Estratégicos (SAE) da Presidência da República (SAE). Brasília: CDS-UnB, Mimeo, 2009. 36 p. SAWYER, D. R.; VAN DER REE, M.; PIRES, M. de 
O. Comercialização de espécies nativas do Cerrado. In: ENCONTRO REGIONAL CENTRO-OESTE, 6., 1997, Brasília. Anais... Brasília: Associação Projeto de Intercâmbio de Pesquisadores Sociais da Agricultura, 1997. p. 149-169.

SEBRAE: SERVIÇO BRASILEIRO DE APOIO ÀS PEQUENAS E MÉDIAS EMPRESAS. Fatores condicionantes e taxas de sobrevivência e mortalidade das micro e pequenas empresas no Brasil 2003-2005. Brasília, 2007. 56 p.

SILVA, F.C.T. da. Conquista e colonização da América Portuguesa: o Brasil Colônia - 1500/1750. In: LINHARES, M.Y. (Org.). História geral do Brasil: da colonização portuguesa à modernização autoritária. Rio de Janeiro: Campus, 1990. p. 33-94. SOUZA, L. A. G.; SILVA, M. F. BioeconomicalpotentialofLeguminosaefromthe Negro river, Amazon, Brasil. In: CONSERVACIÓN DE BIODIVERSIDAD EM LOS ANDES Y LA AMAZONIA. 2002, Inka. Proceedings... Cuzco, 2002, p. 529-538.

UNITED NATIONS/UNITED NATIONS DEVELOPMENT PROGRAMME - UNDP. Humam development report 1998. New York, Oxford: Oxford University Press, 1998. 228 p. Disponívelem: $<$ http://hdr.undp.org/en/ media/hdr_1998_en_definitions.pdf $>$. Acesso em: 08 nov. 2010. 